\section{Lichtzonen beim Zahnarzt}

$\mathrm{D}$ er zahnärztliche Behandlungsraum wird in drei Lichtzonen eingeteilt. Im Umfeld des Untersuchungsstuhls müssen mindestens 500 Lux gewährleistet werden. Der Bereich des Patienten erfordert 1000 Lux, und die Ausleuchtung der Mundhöhle mindestens 5000 Lux. Die Lichtfarbe sollte im gesamten Raum einheitlich neutralweiß oder tageslichtweiß sein. Um Blendungen zu vermeiden, gilt es, bei der Deckenbeleuchtung ein Quadrat mit einer Seitenlänge von 2,5 m um das Sichtfeld des Patienten herum auszusparen und generell nur asymmetrisch strahlende Deckenleuchten einzusetzen.

Quelle: "Gesundheitsfaktor Licht" / licht.de

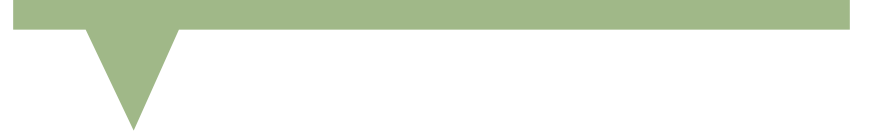

und Geborgenheit mit ein „bisschen Landhausatmosphäre und mittlerem bis hohem Gestaltungsanspruch“. Eine Angst- und Stressfreipraxis strahlt Freundlichkeit, Ruhe und Konzentration aus, ist warmtonig, pastellig und mit hohem Anspruch gestaltet. Bei der Regenerativpraxis liegt der Fokus auf Erholung und Konzentration mithilfe einer fixen Farb- und Formensprache. Die Health \& Care Network Group, ein bundesweit agierendes Gesundheitsdienstleisternetzwerk für Raumgestaltung, hat diese wissenschaftlichen Erkenntnisse in einem Fachbuch veröffentlicht. In Kooperation mit der Hochschule für angewandte Kunst und Wissenschaft Hildesheim wurden nach einem wahrnehmungspsychologischen Konzept Collagenbücher mit Gestaltungsvarianten entworfen. Gelb, grün, rot und orange empfinden Menschen demnach anregend, blau und grün frisch. Rosa ist mit lieblich assoziiert. Auch wenn diese Ansätze auf den ersten Blick naheliegend erscheinen, haben sie einen klaren Vorteil: Sie funktionieren dauerhaft sowie unabhängig von Trend- und Modeerscheinungen.

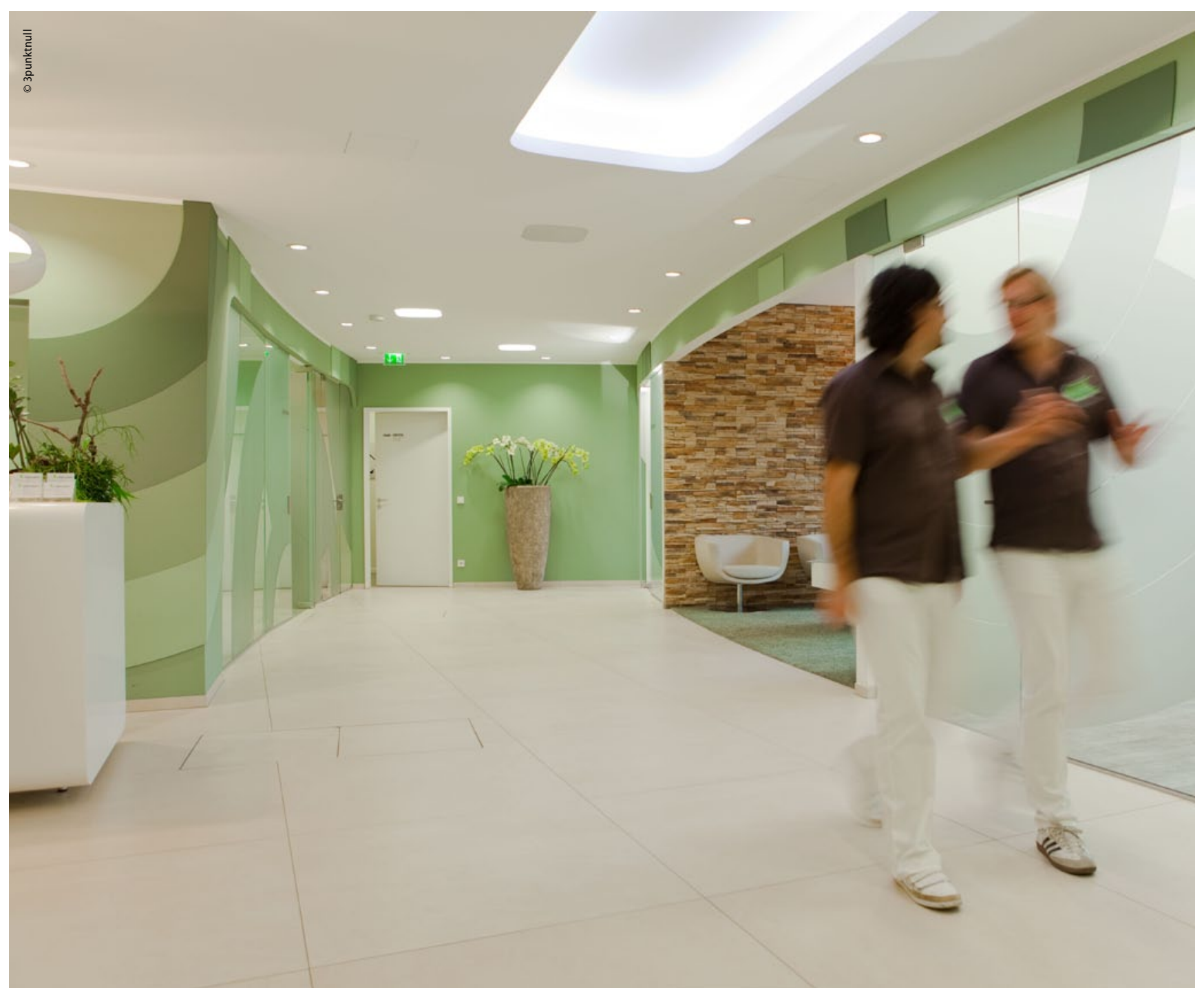

Für ihre Zahnarztpraxis im Kölner Mediapark entschieden sich Dr. Cyrus Alamouti und Dr. André Melchior für viel Transparenz und eine konsequente Farbgestaltung in olivgrün und beige. In der Empfangs-Lounge warten die Patienten bei Kaffee, Zeitschriften, Musik und Fernseher gern. 